\title{
Diffraction studies of aqueous electrolyte solutions
}

\author{
G.W. Neilson \\ Physics Department, Bristol University, Bristol BS8 1TL, England
}

\begin{abstract}
The structural properties of several aqua ions in solution have been determined by neutron and x-ray diffraction. Neutron diffraction combined with isotopic substitution provides direct information about ionic hydration and ion-ion correlations. In particular, systematic studies of different series of ions shows characteristic behaviour which depends on ionic size, charge and electronic configuration.

The relatively new method of X-ray diffraction combined with isomorphic substitution has been applied to $\mathrm{Ni}^{2+} / \mathrm{Mg}^{2+}$ and $\mathrm{Na}^{+} / \mathrm{Ag}^{+}$isomorphic pairs. The results show that the second order difference technique provides a formally exact determination of cation-cation correlations within the isomorphic approximation. The results are consistent with those obtained from the neutron diffraction isotopic difference methods, and pave the way for a more comprehensive investigation of ionic structure in solution as a function of concentration, counterion and pressure and temperature.
\end{abstract}

\section{INTRODUCTION}

Neutron and $X$-ray diffraction methods provide a means by which the structure of an aqueous electrolyte solution can be elucidated (1). This structure is defined in terms of the pair radial distribution functions $g_{\alpha \beta}(r)$ of which there are ten in a system of the general form $\mathrm{MX}_{n_{2}} \mathrm{H}_{2} \mathrm{O}$ : three which pertain to the solvent $-g_{\mathrm{HII}}, \mathrm{g}_{\mathrm{HO}}$, goo, three which are relevant to the solute $g_{n}, g_{M x}, g_{x x}$, and four which refer to correlations between the solute and the solvent $\mathrm{g}_{M O}, \mathrm{~g}_{\mathrm{MH}}, \mathrm{g}_{\mathrm{XO}}, \mathrm{g}_{\mathrm{XH}}$. As will be shown below, each of these functions contributes in varying degrees to a neutron or X-ray scattering pattern (see Fig.1).

It is the object of the experimentalist to determine each of the functions $g$ as precisely as possible in order to have a basic knowledge of the seructure of the solution. However, because of the complexity of an electrolyte solution it is not possible to obtain all this information. Nevertheless, over the past decade, difference methods of neutron and $\mathrm{X}$-ray diffraction have been developed, and we now possess a much more detailed description of the ionic structure of electrolyte solutions (2).

The method of isotopic substitution combined with neutron diffraction allows direct determination of both ion-water structure (the first order difference method), (3) and ion-ion structure (the second order difference method), (4) of the solution. The equivalent method for $x$-ray diffraction based on isomorphic substitution has been introduced to facilitate the determination of quantitative information for ion-ion correlations from a second order difference between diffraction patterns of solutions shown to be isomorphic at the first order difference level (5).

The usefulness of determining the pairwise structure of a solution is underlined by its relevance to ( $i$ ), the systematic categorisation of the relative strengths of ions and (ii) the provision of a means of testing, at the microscopic level, the results of theoretical calculations and computer simulations (6). 


\section{DIFFRACTION METHODS}

As is well established (7), a beam of particles (neutrons or X-rays) of wavelength, $\lambda$ incident on a target, will produce a diffraction pattern, $I(\theta)$ at a scattering angle, $\theta$. After the appropriate data analyses, $I(\theta)$ can be reduced to the structure factor, $F(k)$, where $k=4 \pi \sin (\theta / 2) / \lambda$ is the amplitude of the scattering vector. $F(k)$ contains the basic structural information of the liquid : viz

$$
F(k)=\sum_{\alpha} \sum_{\beta} c_{\alpha} c_{\beta} b_{\alpha} b_{\beta}\left[S_{\alpha \beta}(k)-1\right]
$$

where $c_{\alpha}$ is the concentration of species $\alpha$ whose scattering is characterised by $b_{\alpha}$ For neutron scattering $b_{\alpha}$ is termed the coherent scattering and is independent of $k$ (8). For $x$-ray scattering $b_{\alpha}$ is the atomic form factor and exhibits a strong $k$ dependence (9). The double summation is over all independent scattering species. To distinguish between the $X$-ray and neutron structure factors we use $F(k)$ for the former.

The partial structure factor $\mathrm{S}_{\alpha \beta}(\mathrm{k})$ is related to the Fourier transformation of the radial pair distribution function :

$$
g_{\alpha \beta}(r)-1=1 /\left(2 \pi^{2} \rho r\right) \int\left[s_{\alpha \beta}(k)-1\right] k s i n k r d r
$$

where $\rho=N / V$ is the total number density of the solution and is typically $0.1 \AA^{-3}$

The coordination number of atom $A$ in a shell of thickness $\Delta r$ at $r$ around a central atom $B$ is given by:

$$
\mathrm{n}_{\mathrm{B}}^{\mathrm{A}}=\mathrm{c}_{\mathrm{A}} \rho \leq \pi r^{2} \mathrm{~g}_{\mathrm{AB}}(r) \Delta r
$$

\subsection{DIFFERENCE METHODS}

Fig. 1 shows the relative contributions of the various structural correlations to the neutron and $X$-ray $F(k)$ 's for a concentrated aqueous electrolyte solution. It is obvious from this figure that the possibility of obtaining any information from a neutron diffraction experiment about anything other than the solvent structure is unlikely. It is also unlikely that much information is forthcoming from an $X$-ray diffraction measurement on the same system other than that pertaining to $s_{O O}, s_{X O}, s_{M O}$. Moreover, because the X-ray form factors are k-dependent, it is often not possible to obtain individual $g_{\alpha \beta}(r)$ 's directly because of resolution broadening.
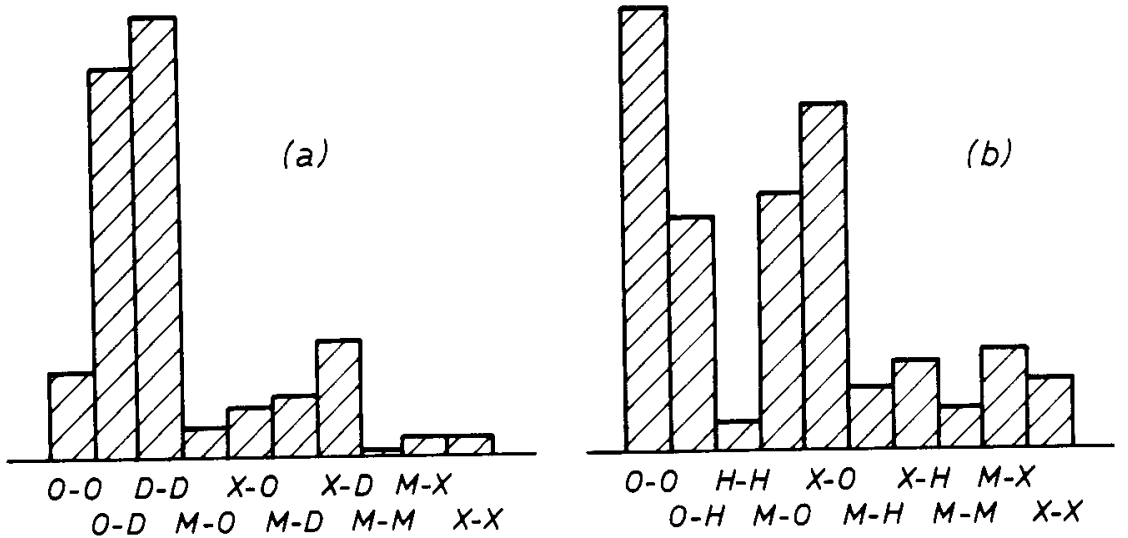

Figs. 1-(a) Relative weighting of the ten pair correlation functions in the neutron diffraction pattern (Equ(1)) of a 4 molar $\mathrm{NiCl}_{2}$ heavy water solution.

-(b) Relative weighting of the ten pair correlation functions in the $X$-ray diffraction $\mathrm{F}(\mathrm{k})$ (Equ.1) of a 4 molar $\mathrm{NiCl}_{2}$ water solution.

In order to progress therefore, one must devise a superior method if we wish to determine ion-water and ion-ion structure. And it is for this reason that the difference methods of diffraction have been developed (Fig.2). 


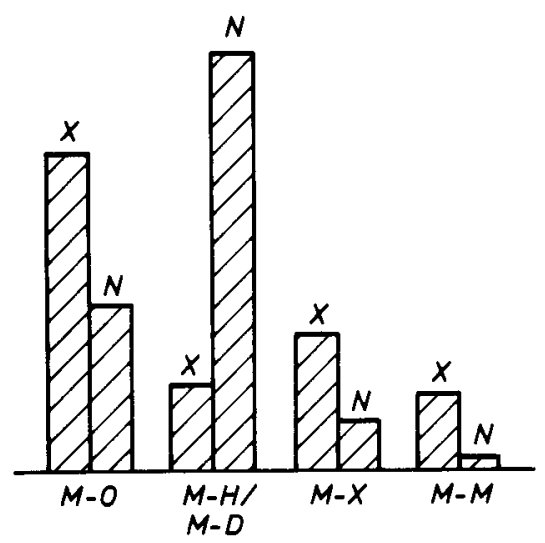

Fig.2. Relative weighting of the 4 pair correlation functions in the $X$-ray (X) and neutron (N) difference functions (Equ.4) for 4 molar $\mathrm{NiCl}_{2}$ in water (X-ray coefficlents are for $k=0$ ).

First order differences: ion-water structure

The first order difference method of neutron diffraction was introduced during the $1970^{\prime} \mathrm{s}$ (3), and since then, many new and useful results have been obtained for the ion-water structure in a variety of solutions (10).

It is a straightforward matter to show (3) from Equ.(2) that if the $F(k)$ 's are obtained for two solutions of the same concentration of electrolyte in heavy water, and whose cation (or anion) differs only in its isotopic state defined by $b$ (i.e. b' and b") then

$$
\begin{aligned}
& \Delta_{M}(k)=F_{1}(k)-F_{2}(k)=A\left(S_{M O}(k)-1\right)+B\left(S_{M D}(k)-1\right) \\
& +C\left(S_{M X}(k)-1\right)+D\left(S_{M M}(k)-1\right) \\
& A=2 c_{M} c_{0} b_{0} \Delta b_{M}, B=2 c_{M} c_{D} b_{D} \Delta b_{M}, C=2 c_{M} c_{X} b_{X} \Delta b_{M} \\
& D=c_{M}^{2} \Delta b_{M}^{2}, \Delta b_{M}=b_{M}^{\prime}-b_{M}^{\prime \prime}, \Delta b_{M}^{2}=b_{M}^{\prime 2}-b_{M}^{\prime 2}
\end{aligned}
$$

Fourier transformation of $\Delta(k)$ gives -

$$
G(r)=A g_{M O}+B g_{M D}+C g_{M X}+D g_{M M}+E
$$

where

$$
E=-(A+B+C+D)
$$

Generally A,B >×C,D and Equ.5 primarily gives information of the ion-water coordination.

(Note. Heavy water solutions are used in neutron diffraction experiments because of its lower incoherent scattering than ordinary water.)

\section{Second order differences: ion-ion coordination}

The second order difference method of neutron diffraction was first applied to a concentrated solution of $\mathrm{NiCl}_{2}$ in heavy water (4). The $\mathrm{NiCl}_{2} \cdot \mathrm{D}_{2} \mathrm{O}$ system is particularly well suited to these types of experiments because of the large number of widely varying $b$ values of $\mathrm{Ni}$ and $\mathrm{Cl}(8)$. The method requires $F(k)$ 's for three isotope substitutions of the cation (or anion), and the analysis yields the ionic p.s.f. $S_{I I}(k)-$

$$
S_{I I}(k)=\frac{1}{c_{I}^{2}\left(b_{I}^{\prime}-b_{I}^{\prime \prime}\right)\left(b_{J}^{\prime}-b_{J}^{\prime \prime}\right)}\left\lceil\frac{F(k)-F(k)}{b_{I}^{\prime}-b_{I}^{\prime \prime}}-\frac{F(k)-F_{4}(k)}{b_{I}^{\prime \prime}-b_{I}^{\prime \prime}}\right\rceil
$$

The cation-anion p.s.f. can be obtained from the $F(k)$ 's of four isotopically distinct cation and anion samples -

$$
S_{I J}(k)=\frac{1}{2 c_{I} c_{J}\left(b_{I}^{\prime}-b_{I}^{\prime \prime}\right)\left(b_{J}^{\prime}-b_{J}^{\prime \prime}\right)}\left[\left(F_{I I}-F_{I I}\right)-\left(F_{1 J}-E_{2 J}\right) \mid\right.
$$
The corresponding pair distribution functions $g_{I I}(r)$ and $g_{I J}(r)$ can be obtained
from Equs.6 and 7 using Equ. 2 . 
Despite the early success of the study of a 4.35 molal solution of $\mathrm{NiCl}_{2}$ in heavy water the $g_{I I}(r)$ has only been obtained in one other solution - 14.9 molal LiCl in heavy water $(11)$. The reasons for this are ( $i$ ) the requirement of long counting times to get data of high statistical accuracy and (ii) the need for economically priced isotopes whose $b$ values are significantly different. It is often the case that no suitable isotopes are available, as, for example, with sodium.

In order to overcome these problems we developed the method of X-ray diffraction with isomorphic substitution. This method is not new and indeed, Bol and co-workers carried out some very significant studies of solutions using this technique (12). However, in their studies, isomorphism was never justified, and their interest was limited to ionic hydration. The method as discussed below aims to show how information of the ion-ion structure can be obtained, and in doing so is justified by reference to neutron diffraction results of ionic hydration, and self consistency checks of $X$-ray results pertaining to the first order difference structure.

To see this we return to the analysis appropriate to the first order difference method, and this time we apply the formalism to X-ray diffraction studies of equimolar solutions of isomorphically distinct atomic species.

At this stage it is worth discussing how isomorphic pairs are initially identified. This is done on the basis of (i) solid state coordination in a particular valence state (13), (Ii) information regarding solution kinetics (14), and (iii) neutron scattering properties that require that one of the species is susceptible to the neutron diffraction first order difference method. A secondary condition is that the isomorphs should be sufficiently well separated in atomic numbers so that reliable differences between $X$-ray diffraction patterns can be obtained. Suitable pairs to date include $\mathrm{Ni}^{2^{+}} / \mathrm{Mg}^{2+}$, and $\mathrm{Na}^{+} / \mathrm{Ag}^{+}$, albeit the isomorphism of the latter pair is only approximate. Other pairs, whose isomorphism is yet to be demonstrated, may include $\mathrm{T}^{+} / \mathrm{Rb}^{+}$and $\mathrm{Cr}^{3+} / \mathrm{Al}^{3+}(15)$.

The isomorphic difference method is also valid for neutron diffraction (16). Indeed, it could be exploited with great effect for elements which do not differ greatly in their position in the periodic table, e.g. the rare earths. However, as we are principally interested in obtaining ion-ion correlations, X-ray diffraction methods are stressed because of the brighter beams available and the non-requirement of expensive isotopically enriched samples.

We now develop the formalism appropriate to the $\mathrm{x}$-ray diffraction isomorphic difference methods (17). It is essentially the same as that for the neutron diffraction methods, but with the important difference that the $b$ 's are k-dependent (9). To distinguish them from the neutron b's we use the form $b x$.

X-ray diffraction data are obtained for two equimolar solutions whose cations (or anions) are isomorphs. The $F(k)^{\prime} s$ of the solutions are calculated and their difference is taken :

$$
\begin{aligned}
& \tilde{\Delta}_{M / M}=F_{1}^{X}(k)-E_{2}^{X}(k)=A^{x}\left(S_{M O}-1\right)+B^{X}\left(S_{M H}-1\right)+C^{x}\left(S_{M X}-1\right)+D^{X}\left(S_{M M}-1\right) \\
& \text { where } \quad A^{x}=2 c_{M} c_{0} b_{0}^{x} \Delta_{M}^{x} M^{\prime}, \quad B^{x}=2 c_{H} c_{M} b_{H}^{x} \Delta x_{M} M^{\prime}, \quad, \quad c^{x}=2 c_{X} c_{M} b_{X}^{x} \Delta_{M / M}^{x} \text {. }
\end{aligned}
$$

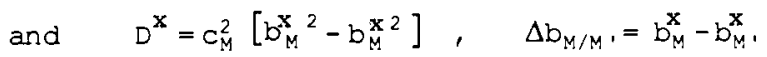

The coefficients A, B, C, D, are functions of $k$, and Fourier transformation of $\Delta_{M / M}(k)$ will not, in general, give a clear picture of the ion water structure. However, Equ. 8 can be used to establish the degree to which $M$ and $M$ ' are isomorphic. This is done by comparing the Fourier transform of $\tilde{\Delta M} M(k) / A^{x}$ and the 'true' $g_{M O}(r)$ as obtained in Equ.2. If the first peak in $g_{M O}(r)$ is well defined, such as in the case of a strongly hydrating cation, the comparison is readily made. Isomorphism is claimed if the $g_{M O}(r)$ obtained from $X$-rays is the same as that obtained from neutrons over the region of the first hydration zone. It is not possible to check the isomorphism beyond this region because of the inherently poor structural resolution beyond the first shell. However, since the main aim of the X-ray difference method is to obtain ion-ion structure and this structure is determined by longer range coulomb effects (17), it is sufficient to have established isomorphism in the first coordination shell around the ion. 
Having demonstrated that $M$ and $M^{\prime}$ are isomorphic, a third X-ray diffraction experiment is carried out on a 50/50 equimolar mixture of $\mathrm{MX}_{\mathbf{n}} \cdot \mathrm{H}_{2} \mathrm{O}$ and $\mathrm{M}^{\prime} \mathrm{X}_{\mathbf{n}} \cdot \mathrm{H}_{2} \mathrm{O}$. The $F(k)$ of this solution is determined and combined with the other two $F(k)$ 's of the individual solutions to give, within the isomorphic approximation, a formally exact equation for the p.s.f. $\mathrm{S}_{M M}(k)$, viz

$$
S_{M M}(k)=\frac{1}{c_{M}^{2}\left(b_{M}^{x},-b_{M / M}^{x}\right.} \cdot\left[\frac{F_{1}^{x}-F^{x}}{b x-b_{M}^{x}}-\frac{F_{1}^{x}-F_{3}^{x}}{b_{M}^{x}-b_{M / M}^{x}}, \mid\right.
$$

where $b_{M} \mathbf{x}$, is the appropriate atomic form factor for the mixture, i.e.

$$
b_{M / M}^{X}, \quad b_{M / M}^{x}=\frac{b_{M}^{X}+b_{M}^{X}}{2}
$$

The results of the third solution may also be used to provide additional

confirmation of the isomorphism between $M$ and $\mathrm{M}^{\prime}$. This is done by comparing Fourier transforms of two first order differences, $\left(F_{1}^{x_{1}}-F_{2}^{x}\right) / A$ and $\left(F_{1}^{x}-F_{3}^{x}\right) /\left(A A^{x}\right)$ say. If these are self consistent in terms of the nearest neighbour ion-oxygen correlation, then $M$ and $M^{\prime}$ are isomorphic.

In summary, the main advantage of the isomorphic method as applied to $\mathrm{X}$-ray diffraction is that a systematic series of experiments over a wide range of $p, T$, ionic concentration, and counterion type can be undertaken economically in a relatively short period of time.

\section{RESULTS AND DISCUSSION}

\subsection{IONIC HYDRATION}

Tables 1 and 2 list the ion- $\mathrm{D}_{2} \mathrm{O}$ coordination properties for all ions so far studied by the neutron diffraction first order difference technique. There is a rich variety of behaviour for these ions and in many cases the trends observed confirm model structures proposed on the basis of spectroscopic and thermodynamic studies (19). The results also provide theorists with a useful test of both model potential calculations (20) and computer simulation procedures (21).

\begin{tabular}{|c|c|c|c|c|c|c|c|}
\hline Ion & Solute & Molality & $\begin{array}{l}\text { Ion-oxygen } \\
\text { distance }(\AA)\end{array}$ & $\begin{array}{l}\text { Ion-deuterium } \\
\text { distance }(\AA)\end{array}$ & $\theta(\operatorname{deg})$ & $\begin{array}{l}\text { Hydration } \\
\text { number }\end{array}$ & Reference \\
\hline $\mathrm{Ii}^{+}$ & LiCl & $\begin{array}{r}27.77 \\
9.95 \\
3.57\end{array}$ & $\begin{array}{l}1.95 \pm 0.02 \\
1.95 \pm 0.02 \\
1.95 \pm 0.02\end{array}$ & $\begin{array}{l}2.31 \pm 0.02 \\
2.50 \pm 0.02 \\
2.55 \pm 0.02\end{array}$ & $\begin{array}{l}75 \pm 5 \\
52 \pm 5 \\
40 \pm 5\end{array}$ & $\begin{array}{l}2.3 \pm 0.2 \\
3.0 \pm 0.5 \\
5.5 \pm 0.3\end{array}$ & $(22)$ \\
\hline$x^{+}$ & $\mathrm{KC} \ell$ & 4.0 & $2.60 \pm 0.1$ & $3.0-3.2$ & - & $4.2 \pm 0.4$ & (23) \\
\hline \multirow[t]{2}{*}{$\mathrm{Ag}^{+}$} & $\mathrm{AgNO}_{3}$ & 3.6 & $2.50 \pm 0.03$ & $2.92 \pm 0.04$ & & $3.7=0.3$ & $(24)$ \\
\hline & $\mathrm{AgClO}_{4}$ & 4.0 & $2.41 \pm 0.02$ & $2.97 \pm 0.04$ & $45^{\circ} \pm 4^{\circ}$ & $4.1 \pm 0.3$ & (4) \\
\hline \multirow[t]{2}{*}{$\mathrm{ND}_{4}^{+}$} & $\mathrm{ND}_{4} \mathrm{Cl}$ & 5.0 & $2.8-3.2$ & $3.4-3.8$ & - & $10.0-12.0$ & \\
\hline & $\mathrm{ND}_{4} \mathrm{NO}_{3}$ & 12.0 & $2.8-3.2$ & $3.4-3.8$ & & $7.0 \pm 0.5$ & $(26)$ \\
\hline $\mathrm{Ca}^{2+}$ & $\mathrm{CaCl}_{2}$ & $\begin{array}{l}4.49 \\
2.80 \\
1.0\end{array}$ & $\begin{array}{l}2.41 \pm 0.03 \\
2.39 \pm 0.02 \\
2.46 \pm 0.03\end{array}$ & $\begin{array}{l}3.04 \pm 0.03 \\
3.02 \pm 0.03 \\
3.07 \pm 0.03\end{array}$ & $\begin{array}{l}34 \pm 9 \\
34 \pm 9 \\
38 \pm 9\end{array}$ & $\begin{array}{r}6.4 \pm 0.3 \\
7.2 \pm 0.2 \\
10.0 \pm 0.6\end{array}$ & (27) \\
\hline $\mathrm{Ni}^{2+}$ & $\mathrm{NiCl}_{2}$ & $\begin{array}{l}4.41 \\
3.05 \\
1.46 \\
0.85 \\
0.42 \\
0.086\end{array}$ & $\begin{array}{l}2.07 \pm 0.02 \\
2.07 \pm 0.02 \\
2.07 \pm 0.02 \\
2.09 \pm 0.02 \\
2.10 \pm 0.02 \\
2.07 \pm 0.03\end{array}$ & $\begin{array}{l}2.67 \pm 0.02 \\
2.67 \pm 0.02 \\
2.67 \pm 0.02 \\
2.76 \pm 0.02 \\
2.80 \pm 0.02 \\
2.80 \pm 0.04\end{array}$ & $\begin{aligned} 42 & \pm 8 \\
42 & \pm 8 \\
42 & \pm 8 \\
27 & \pm 10 \\
17 & \pm 10 \\
0 & \pm 20^{\circ}\end{aligned}$ & $\begin{array}{l}5.8 \pm 0.2 \\
5.8 \pm 0.2 \\
5.8 \pm 0.3 \\
6.6 \pm 0.5 \\
6.8 \pm 0.8 \\
6.8 \pm 0.8\end{array}$ & $\begin{array}{r}(4) \\
(28)\end{array}$ \\
\hline $\mathrm{Ni}^{2+}$ & $\mathrm{Ni}\left(\mathrm{C}_{2} \mathrm{O}_{4}\right)_{2}$ & 3.80 & $2.07 \pm 0.02$ & $2.67 \pm 0.02$ & $42 \pm 8$ & $5.8 \pm 0.2$ & (29) \\
\hline \multirow[t]{3}{*}{$\mathrm{Cu}^{2+}$} & $\mathrm{CuCl}_{2}$ & 4.32 & $1.96 \pm 0.03$ & $2.58 \pm 0.03$ & $38 \pm 6$ & $3.6 \pm 0.3$ & (30) \\
\hline & $\mathrm{Cu}\left(\mathrm{ClO}_{4}\right)_{2}$ & 2.00 & $1.96 \pm 0.04$ & $2.58 \pm 0.03$ & $38 \pm 6$ & $4.1 \pm 0.3$ & \\
\hline & $\mathrm{Cu}\left(\mathrm{NO}_{3}\right)_{2}$ & $1 . \infty$ & $1.96 \pm 0.03$ & $2.58 \pm 0.03$ & $38 \pm 6$ & $3.8 \pm 0.2$ & \\
\hline $\mathrm{Nd}^{3+}$ & $\mathrm{NaCl}_{3}$ & 2.85 & $2.48 \pm 0.02$ & $3.13 \pm 0.02$ & $24 \pm 4$ & $8.5 \pm 0.2$ & (31) \\
\hline $\mathrm{Dy}^{3+}$ & $\mathrm{DyCl}_{3}$ & 2.38 & $2.37 \pm 0.03$ & $3.04 \pm 0.03$ & $17 \pm 3$ & $7.4 \pm 0.5$ & (32) \\
\hline
\end{tabular}

TABLE 1. Cation hydration at roon temperature as deternined by neutron diffraction 
TABLE 2. Chloride and perchlorate ion hydration at room temperature as determined hy neutron diffraction.

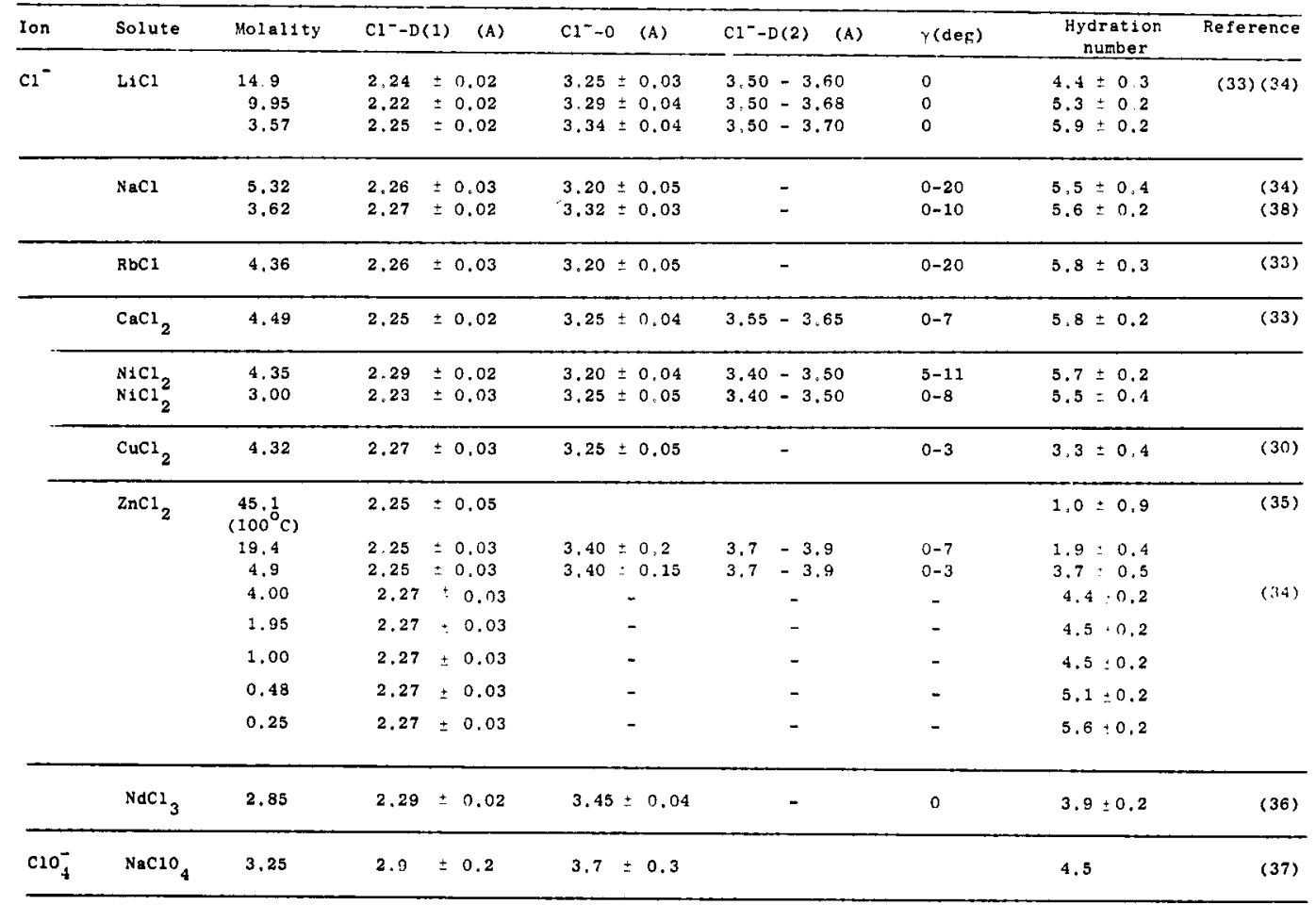

Typical $G(r)$ 's are shown in Figs. 3 and 4 for the ion water structure of a strong cation, $\mathrm{Ni}^{2+},(28)$ and an anion $\mathrm{Cl}^{-}(33)$. As can be seen in the insets both these ions possess a well-defined local conformation. Cations such as $\mathrm{Li}^{+}$and $\mathrm{Ca}^{2+}$ and to a lesser extent $\mathrm{Cu}^{2+}$ have a similarly well-defined conformation to $\mathrm{Ni}^{2+}$. However, such is not the case in general, especially for $\mathrm{K}^{+}(23)$ or for complex ions such as $\mathrm{ND}_{4}^{+}(25), \mathrm{NO}_{3}^{-}(36), \mathrm{ClO}_{4}^{-(37)}$.

Almost all the results in Tables 1 and 2 have been discussed in detail elsewhere (10), and rather than discuss them further here, I shall instead refer to some recent studies which are about to be published or are in the process of analysis.

of particular interest recently has ben an investigation of $\mathrm{Cu}^{2+}$ where we have demonstrated the dependence of the $\mathrm{Cu}^{2+}$ hydration on both counterion and concentration. Furthermore, we have shown that in order to explain the results of a 4.3 molal $\mathrm{CuCl}_{2}$ heavy water solution, there must be direct contacts between $\mathrm{Cu}^{2+}$ and $\mathrm{Cl}^{-}(30)$.

The behaviour of $\mathrm{Fe}^{2+}$ and $\mathrm{Fe}^{3+}$ in solution science has been of long historical interest (39). During the past two years we have been investigating the coordination of $\mathrm{Fe}$ and found it to be strongly dependent on counterion type and $\mathrm{pH}$ (40). In highly acidic aqueous perchlorate solution at $\mathrm{pH} \sim 0$ there is evidence of a six fold coordination and a degree of hydrolysis. In aqueous nitrate solutions at similar concentrations and $\mathrm{pH}$, hydrolysis is also observed. However, there is only a five fold $\mathrm{Fe}^{3+}-0$ coordination $(40)$.

The properties of 'hard' ions such as $\mathrm{Ni}^{2+}$ and $\mathrm{Ii}^{+}$in more complex solutions is the subject of current investigation. We have recently shown that in a solution of Ni-adenosine triphosphate in heavy water that the $\mathrm{Ni}^{2+}$ ion binds directly to the triphosphate group (41), confirming indirect spectroscopic studies. A study is also underway on the properties of $\mathrm{Li}^{+}$coordination in solutions of LioD/polyacrylic acid/heavy water, where the interest is in the degree to which $\mathrm{Li}^{+}$coordinates to the polyelectrolyte.

The generality of the first order difference method is further underlined by the fact that work can also be undertaken on non-aqueous electrolyte solutions, and indeed a study is underway of the $\mathrm{Ni}^{2+}$ coordination in methanol and formanide. The aim of these studies is to determine the dependence of BNiNi( $r$ ) on dielectric constant. 


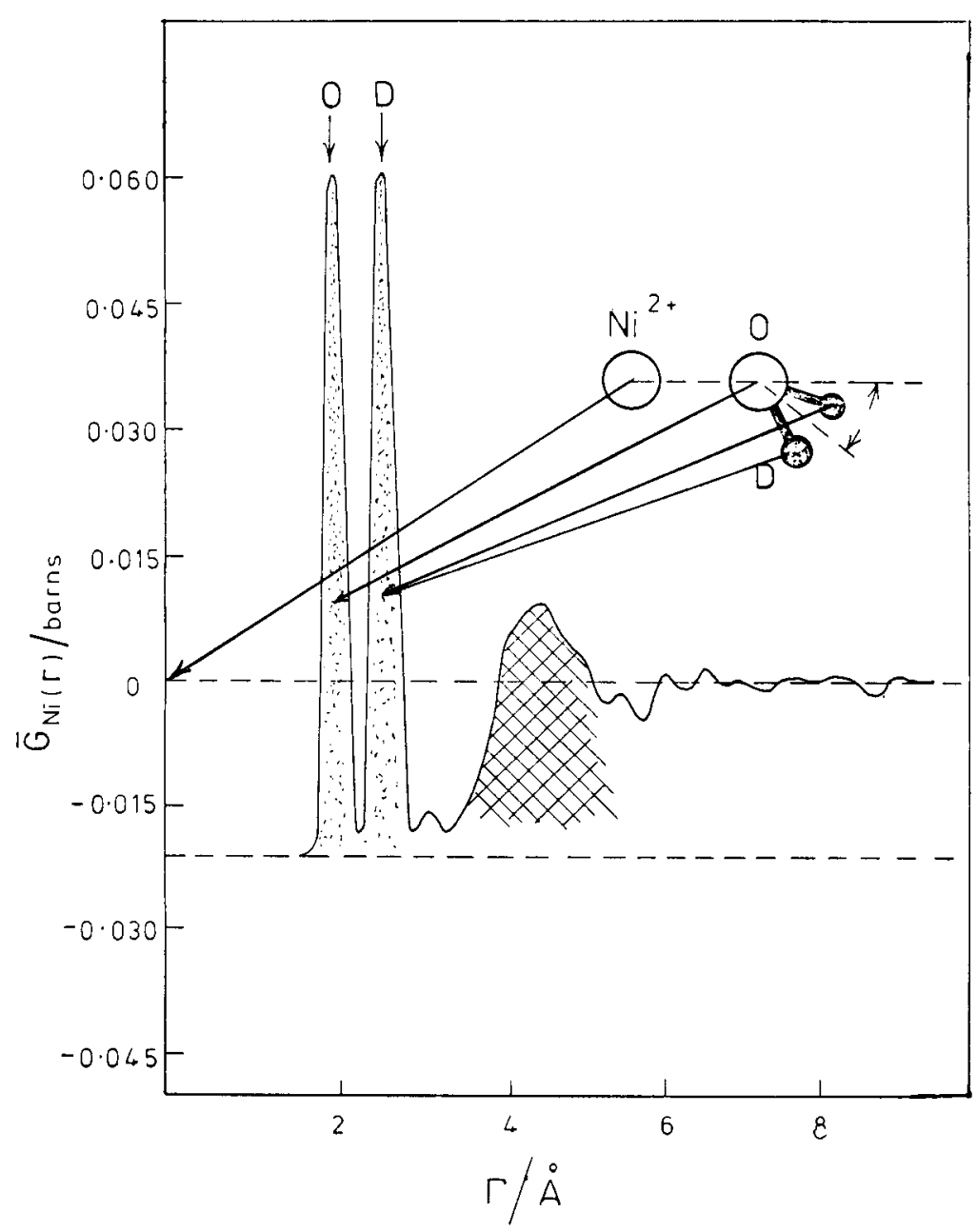

Fig.3. The total nickel ion radial distribution function, $\overline{\mathrm{G}}_{\mathrm{Ni}}(r)$, for 1.46 molal solution of nickel chloride in heavy water (ref.28)

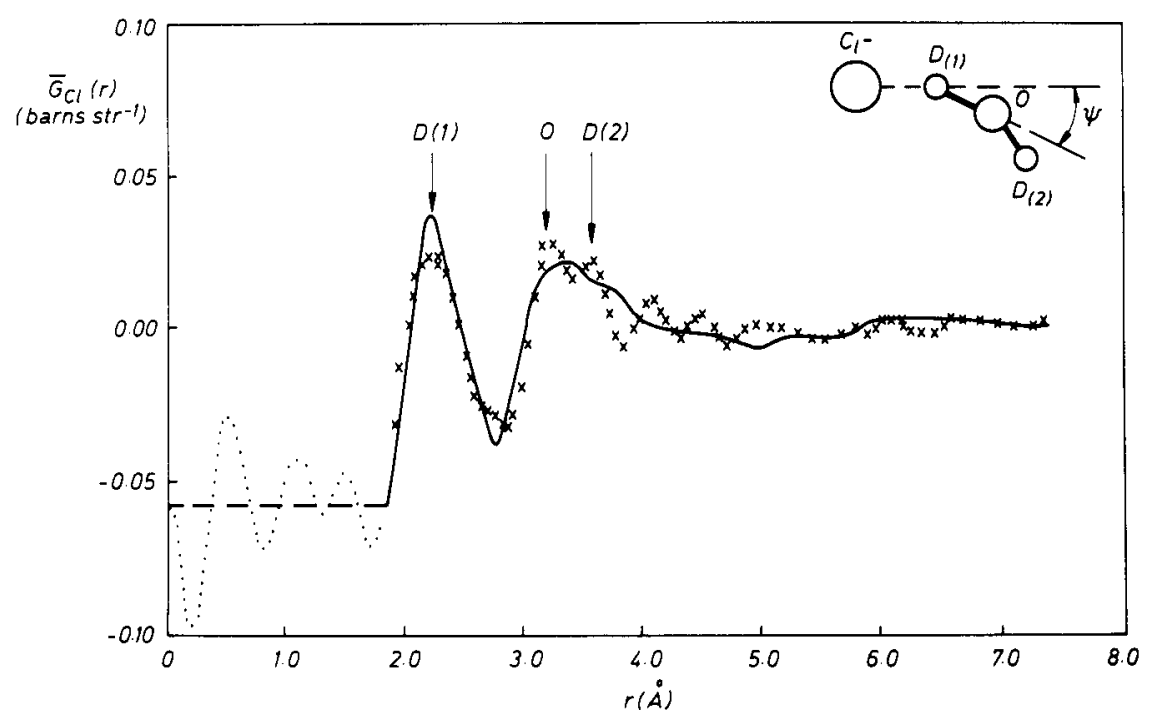

Fig.4. The total chloride ion radial distribution function $\bar{G}_{\mathrm{C} \ell}(r)$ for (a) 9.95 molal LiCl in heavy water (full curve) and (b) 5.32 molal NaCl in heavy water (crossed curve), scaled for concentration by 1.87 . 
Although the isomorphic method of X-ray diffraction is primarily aimed at the determination of ion-ion structure in solution, for the case of $\mathrm{Na}$ where the neutron difference method is not useable, and the nature of $\mathrm{Na}^{+}$hydration is of fundamental interest in biology (41), an attempt has been made to obtain an approximate understanding of $\mathrm{Na}^{+}-$water coordination using the isomorphic pair $\mathrm{Na}^{+}$ $/ \mathrm{Ag}^{+}$. The isomorphism proposed is at best approximate. However, aqueous solutions of sodium nitrate and silver nitrate have many structural and thermodynamic properties in common (43). Furthermore, there is a high degree of self-consistency in the $X$-ray difference functions to support the proposed isomorphism (36). A study of 3.1 molar solutions shows that the $\mathrm{Na}^{+} / \mathrm{Ag}^{+}$hydration is intermediate between that of $\mathrm{Li}^{+}(22)$ and $\mathrm{K}^{+}(23)$, and is much as expected on the basis of models inferred from spectroscopic and thermodynamic measurements.

\subsection{ION-ION CORRELATIONS}

As mentioned earlier, individual partial structure factors have so far only been determined in concentrated solutions of nickel chloride (4) and lithium chloride (11). It was found that the experimentally derived cation-cation distribution function was in excellent agreement with that obtained from primitive model (P.M.) calculations applied to Monte Carlo simulations (44) and hypernetted chain theory (45).

By contrast, P.M. calculations of $\mathrm{g}_{\mathrm{ClCl}}(r)$ deviate greatly from the experimental results for both solutions, a consequence we believe of the strong directionality of the $\mathrm{Cl}^{-}-\mathrm{H}_{2} \mathrm{O}$ potential (4).

The recently developed $x$-ray diffraction difference method of isomorphic substitution has enabled us to widen our studies of ion-ion structure. Naturally, the first study using this technique was on solutions of nickel chloride and magnesium chloride. The choice of $\mathrm{Ni}^{2+} / \mathrm{Mg}^{2+}$ as an isomorphic pair was made on the basis of similar structural (13) and thermodynamic (14) properties solution. Although it is clear that $\mathrm{Ni}$ has a wider range of isotopes, and $\mathrm{g}_{\mathrm{NiNi}}(r)$ is in principle better determined by neutron diffraction methods, because of the inherently weak neutron intensity compared with a laboratory X-ray source the calculated $g_{\mathrm{NiNi}}(r)$ from the X-ray method is of higher quality than that from neutrons (Fig.5). Moreover, because of the versatility of the X-ray methods and favourable conditioning of Equ. ( 9 ), we have been able to study $g_{\mathrm{NiNi}}(r)=\left(g_{\mathrm{MgNg}}(r)\right)$ as a function of ionic concentration and counterion $(17,46)$.

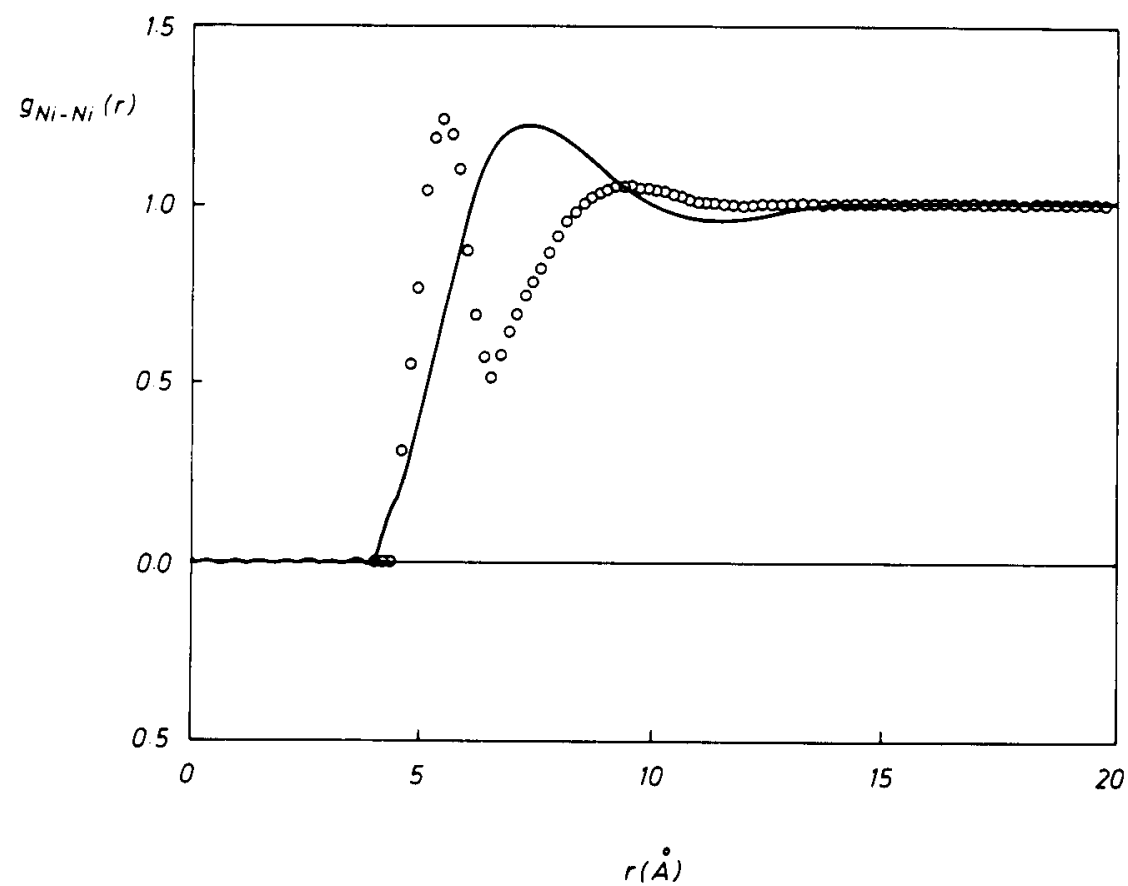

Fig.5. The cation-cation distribution function in 4.35 molal aqueous nickel chloride solution: full curve as determined from $X-r a y$ diffraction; dotted curve as determined from neutron diffraction. See text and ref.10, for explanation of difference between two results. 
As mentioned above an X-ray diffraction study was made of 3.1 molar aqueous solution of sodium and silver nitrate where the isomorphic difference technique was applied to the $\mathrm{Na}^{+} / \mathrm{Ag}^{+}$pair. The results show $(17,47)$ that $g_{\mathrm{NaNa}}(r)=g_{\mathrm{AgAg}}(r)$ is a much stronger function than $\mathrm{g}_{\mathrm{NiNi}}(r)$ in aqueous $\mathrm{NiCl}_{2}$ solution (4). Ag This result could well be due to the counterion present, and we are presently investigating $\mathrm{g}_{\mathrm{NiNi}}(r)$ as a function of counterion type.

\section{CONCLUSIONS AND FUTURE PROSPECTS}

The difference methods of $\mathrm{X}$-ray and neutron diffraction have been instrumental in deepening our understanding of the microscopic properties of complex liquids. They offer a means by which the relative strengths of ions can be categorised in a systematic way. Furthermore, results concerning ionic structure in terms of pair radial distribution functions and partial structure factors provide a sensitive means of checking the validity of theoretical calculations and computer simulation of specific models of the liquid.

In the past two years there have been several significant technological developments including the commissioning of a new intense pulsed neutron source at Rutherford Appleton Laboratory (U.K.) and the upgrading of the Synchrotron Radiation Source at Daresbury (U.K.). The instruments on these sources will use the latest generation of detectors and computing systems, and enable us to apply the difference methods of diffraction more widely. For example, it is anticipated that this situation will enable us to improve the quality of the results of systems described in this article, and extend our studies to a wider range of ever more complex systems under a variety of physical and chemical conditions.

\section{Acknowledgements}

The work presented in this paper represents a combined effort over the past decade of colleagues at Bristol University. It is a particular pleasure to thank Professor John Enderby, whose enthusiasm and encouragement have done so much to make this programme a success. I am also grateful to Dr. Neal Skipper who carried out most of the X-ray work referred to in the text and $\mathrm{Mr}$. John Herdman for access to unpublished results of neutron diffraction studies of $\mathrm{Fe}^{3+}$. Finally, I thank S.E.R.C. for their continuing financial support.

\section{REFERENCES}

1. J.E. Enderby and G.W. Neilson, Water, a comprehensive treatise, (Ed. F. Franks), Vol.6, Chap.1, Plenum Press, N.Y. (1979).

2. J.E. Enderby in Aqueous Ionic Solutions (Eds. Bellisent-Funel and Neilson), p.129, NATO ASI, Series C.205, Reidl, Dordrecht (1987).

3. A.K. Soper, G.W. Neilson, J.E. Enderby and R.A. Howe, J. Phys. C: Solid State Phys., 10, 1793-1801 (1977).

4. G.W. Neilson and J.E. Enderby, Proc. Roy. Soc., A393, 353-371 (1983).

5. N.T. Skipper, S. Cummings, G.W. Neilson and J.E. Enderby, Nature, $321,52-53(1986)$.

6. See e.g. J.E. Enderby and G.W. Neilson, Repts. on Prog. in Physics, $44(1981), 593-653$.

7. G. Squires, Introduction to the Theory of Thermal Neutron Scattering, CUP, Cambridge (1978).

8. V.F. Sears, Table of Neutron Coherent Scattering Lengths. A.E.C.I., 8490 Chalk River National Laboratories, Canada (1984).

9. X-ray Crysta1lography, International Tables (X.C.I.T.) Vol.III (1962), Vol.IV (1974), Kynoch Press.

10. J.E. Enderby, S. Cumings, G.J. Herdman, G.W. Neilson, P.S. Salmon and N.T. Skipper, J. Phys. Chem., 91, 5851 (1987).

11. A.P. Copestake, G.W. Neilson and J.E. Enderby, J. Phys. C: Solid State Phys., 18, 4211 (1985).

12. W. Boi, G.T.A. Gerrits and C.L. van P. van Eck., Acta Cryst., $\underline{3}$, $486(1970)$.

13. R.D. Shannon and C.T. Prewitt, Acta Cryst., B25, 925 (1969).

14. See e.g. Cotton and Wilkinson, Inorganic Chemistry, 4th Edn. Wiley Interscience, NY (1980).

15. M. Sandstrom. Private communication.

16. G.W. Neilson, J.R. Newsome and M. Sandstrom, J. Chem. Soc. Faraday, Trans. II, 77, $1245(1981)$.

17. N.T. Skipper. Ph.D. Thesis. Bristol University (1987). 
18. J.E. Enderby and G.W. Neilson, Adv. in Physics.

19. See e.g. O.M. Bockris and A.K.N. Reddy, Modern Electrochemistry, Vo1.1, Chap.2, Plenum Press, N.Y. (1970).

20. H.L. Friedman in Aqueous Ionic Solutions (Eds. Bellisent-Funel and Neilson), p.61. NAT0 ASI, Series C.205, Reid1, Dordrecht (1987).

21. P. Bopp. void. p.217.

22. J.R. Newsome, G.W. Neilson and J.E. Enderby. J. Phys. C: Solid State Phys., 13, L923 (1980).

23. G.W. Neilson and N.T. Skipper, Chem. Phys. Lett, 122, 475 (1985).

24. M. Sandstrom, G.W. Neilson, G. Johannson and T. Yamaguchi. J. Phys.C: Solid State Phys. 18, Ll115 (1985).

25. N.A. Hewish and G. W. Neilson, Chem. Phys. Lett. 84,425 (1981).

26. P.A.M. Walker, D. Lawrence, G. $\bar{W}$. Neilson and J. Cooper, si:bmitted to J.C.S. Faraday I.

27. N.A. Hewish, G.W. Neilson and J.E. Enderby. Nature, 297, 138 (1982).

28. G.W. Neilson and J.E. Enderby, J. Phys. C: Solid State Phys. 11, L625 (1978).

29. J.R. Newsome, G.W. Neilson, J.E. Enderby and M. Sandstrom, Chem. Phys. Lett. 82, 399 (1981).

30. P.S. Salmon, G.W. Neilson and J.E. Enderby. J. Phys. C: Solid State Phys. 21, 1335 (1988).

31. A.H. Narten and R.L. Hahn, Science 217, 1245 (1982).

32. B.K. Annis, R.I. Hahn and A.H. Narten, J. Chem. Phys. 82, 2806 (1985).

33. S. Cummings, J.E. Enderby, G.W. Neilson, J.R. Newsome, R.A. Howe, W.S. Howells and A.K. Soper, Nature 287, 714 (1980).

34. D.H. Powell, A. Barnes, J.E. Enderby, G.W. Neilson and P.S. Salmon, Faraday Discussion, 85, Solvation (1988) in press.

35. S. Biggin, ISAS report, 16/86/CM, Trieste (1986).

36. S. Biggin, J.E. Enderby, R.L. Hahn and A.H. Narten, J. Phys. Chem. 88,3634 (1984).

37. G.W. Neilson, D. Schioberg and W.A.P. Luck, Chem. Phys. Lett. 122 , 475 (1985).

38. G.W. Neilson and J.E. Enderby, J. Phys. C: Solid State Phys. 15, 2347 (1981)

39. J. Burgess in Metal Ions in Solution, p.434, Ellis Harwood Ltd., Chichester, U. K. (1978).

40. G.J. Herdman and G.W. Neilson, unpublished results. Institut Laue Langevin Reports (1986) p.203 and (1987).

41. P.M.N. Gullidge and G.W. Neilson. Ifstitut Laue Langevin Report (1986) p.300. Manuscript submitted for publication.

42. J. Koryta, Ions, Electrodes and Membranes, p.165. Wiley, New York (1982).

43. Davies, Ion Association, p.168, Butterworths, London (1986).

44. H.L. Friedman and J.B. Dudowicz, Aust. J. Chem. 33, 1889 (1980).

45. A.P. Copestake, Ph.D. Thesis, University of Bristol (1983).

46. N.T. Skipper, G.W. Neilson and S. Cummings. Manuscript in preparation.

47. N.T. Skipper and G.W. Neilson. Manuscript in preparation. 